\title{
Membrane Structural Condition and Functional Activity of Peritoneal Macrophages after Gas Discharge Exposure
}

\author{
DOI: 10.17691/stm2017.9.3.07
}

Received February 7, 2017

E.V. Arkhipova, Junior Researcher, Biochemistry Unit, Central Research Laboratory;

I.P. Ivanova, DSc, Head of Physicochemical Research Department, Central Research Laboratory

Nizhny Novgorod State Medical Academy, 10/1 Minin and Pozharsky Square, Nizhny Novgorod, 603005, Russian Federation

The aim of the investigation was to study in experiment the impact of gas discharge (spark plasma and UV radiation of a quartz lamp) radiation on a membrane structural condition and functional activity of peritoneal macrophages.

Materials and Methods. The target of the research was peritoneal macrophages of Wistar rats. A gas discharge Pilimin device series IR-10 and an DBK-9 UV lamp as were used as an operative factor. The suspension of peritoneal macrophages was treated within 30,60 300,600 , and 1,200 s. Lipid composition was studied by thin-layer chromatography. Microviscosity in lipid-lipid and protein-lipid interaction areas was analyzed by pyrene fluorescence. Hydrophobicity of membrane hydrocarbon layer was determined by 1,6-diphenyl-1,3,5hexatrien fluorescence. To assess the functional state of peritoneal macrophages we studied latex particle absorption phagocytosis activity, oxygen-dependent metabolism condition by nitro blue tetrazolium reduction test and by measuring luminal-dependent chemiluminescence.

Results. The study showed phospholipid oxidation to be less intensive under spark plasma radiation than when exposed to UV lamp radiation. Membrane microviscosity in lipid-lipid and protein-lipid interaction areas increases to a greater extent after UV lamp radiation exposure. The density of fatty acids of phospholipids decreases after spark plasma radiation and increases when exposed to UV lamp radiation. Spark plasma radiation causes the expansion in the number of cells participating in phagocytosis, the increase of absorbing capacity and oxygen-dependent metabolism of peritoneal macrophages. "Oxygen explosion" time of macrophages decreases after plasma radiation exposure, but increases after UV lamp radiation exposure.

Conclusion. Spark plasma radiation compared to UV lamp radiation contributes to the enhancement of phagocytic activity of peritoneal macrophages in less continuous modes, the effects under study being more pronounced. The study findings enable to reveal optimal modes for functional cell activity after gas discharge exposure.

Key words: gas-discharge devices; peritoneal macrophages; study of spark plasma; UV radiation; membrane microviscosity; membrane hydrophobicity.

The cells of mononuclear phagocytes are of great importance for maintaining body resistance. The immune response intensity and body homeostasis depend on their functional activity [1]. Macrophage structural organization and membrane integrity have an impact on intracellular processes and various metabolic reactions. The condition of cell membrane structural components, their position and interaction determine the biophysical properties of membranes, and therefore, the capabilities of receptor apparatus, integrity and adequate functioning of mononuclear phagocytes $[2,3]$. All the above determines the study of physicochemical factors, which enable to enhance the phagocytic activity in infectious or neoplastic processes. In the last decade, biological effects of cold gas discharge plasma have been investigated $[4,5]$. There have been found a bactericidal, cytotoxic effect, as well as the activation of mononuclear cells after gas discharge plasma radiation [5-8]. Gas discharge plasma radiation was shown to influence selectively structural-functional components of cell membranes, for instance, it results in no accumulation of molecular products of lipid peroxidation, however, causing oxidative protein modification $[9$, 10]. When generating gas discharge plasma radiation, UV range, in particular, radical products are formed, which participate in reduction-oxidation reactions. Oxidizers and deoxidizers influence the modification of macromolecules and metabolic processes in a cell $[11,12]$. The study and analysis of the effect of gas discharge plasma radiation and UV lamp radiation on macrophage membrane appear to be interesting, it will enable to reveal the mechanism of their modification after the exposure.

The aim of the investigation was to study the impact of gas discharge radiation and UV radiation of a quartz lamp on a membrane structural condition and functional activity of peritoneal macrophages.

Materials and Methods. In vitro experiments were carried out. Peritoneal macrophages of Wistar rats were the research objects. Macrophage suspension

For contacts: Eugenia V. Arkhipova, e-mail: arhipova@nnovgorod.ru 
was obtained 20 min after intraperitoneal administration of sterile saline solution. UV radiation was generated by a DBK-9 UV quartz lamp (Solnyshko, Russia). The spectrum pattern of DBK-9 is monochromatic, the maximum being at $\lambda=254 \mathrm{~nm}$, continuous power is $9 \mathrm{~W}$, an average photon flux is $5.4 \cdot 10^{-8} \mathrm{~mol}\left(\mathrm{~cm}^{2} \cdot \mathrm{s}\right)^{-1}$. Spark plasma radiation was generated by an experimental device Pilimin series IR-10 (Skobeltsyn Institute of Nuclear Physics, Lomonosov Moscow State University, Russia) with the pre-set parameters: pulse time is $100 \mu \mathrm{s}$, supply voltage is $11 \mathrm{kV}$, pulse capacitor capacity is $3.3 \mathrm{nF}$, pulse energy is $5.9 \cdot 10^{-2} \mathrm{~J}$, frequency is $10 \mathrm{~Hz}$, continuous radiation spectrum with maximum $\lambda=220 \mathrm{~nm}$, average photon flux is $(1.26 \pm 0.2) 10^{-10} \mathrm{~mol}\left(\mathrm{~cm}^{2} \cdot \mathrm{s}\right)^{-1}$. The suspension of peritoneal macrophages was treated within $30,60,300,600$, and 1,200 s. Intact cells served as controls.

At the first research stage we assessed the structural condition of peritoneal macrophage membranes before and after gas discharge exposure: a lipid composition, microviscosity, and hydrophobicity. The lipid composition was analyzed using thin-layer chromatography by successive application of two solvent systems [12]. The chromatograms taken were analyzed and quantitatively processed using GelAnalyzer 2010a. The amount of lipid fractions was taken as 100\%, the percentage of each lipid type being determined. In addition, we calculated the ratio of cholesterol fraction to total phospholipids (CS/PL). Microviscosity of macrophage membranes in lipid-lipid and protein-lipid interactions was estimated by recording lateral diffusion of a hydrophobic pyrene probe (Sigma-Aldrich, USA). An eximerization coefficient is inversely dependent on microviscosity and calculated by the formula $C_{e x}=F_{470} l$ $F_{395}$ [13], where $F$ is fluorescence at wavelength of 470 and $395 \mathrm{~nm}$. Hydrophobicity degree was analyzed by the fluorescence of 1,6-diphenyl-1,3,5-hexatrien probe (Sigma-Aldrich, USA) [14]. Fluorescent spectra of membrane probes were recorded by a Fluorat-02Panorama spectrofluorometer (Lumex, Russia).

During the second research stage we studied the functional state of peritoneal macrophages before and after exposure. Phagocytic activity was estimated by the absorption of $0.8-\mu \mathrm{m}$ latex particles. We calculated the percentage of active cells (phagocytic index) and the average number of latex particles absorbed by a phagocyte (phagocytic number). Metabolic activity was assessed by the findings of spontaneous and zymosanactivated nitro blue tetrazolium tests (NBT test) [7]. The functional activity of peritoneal macrophages was determined by measuring luminal-dependent chemiluminescence using a Luminoskan Ascent microplate luminometer (Thermo Fisher Scientific, Finland). We carried out two parallel tests: spontaneous and induced by a stimulator (phytohemagglutinin, $200 \mu \mathrm{g} / \mathrm{ml}$ ), the measurements being made within $30 \mathrm{~min}$. We took into consideration the result at the peak of chemiluminescence and when its maximum was attained.
The results were presented as $M \pm m$, where $M$ is arithmetic mean, and $m$ is standard error of the mean. Mann-Whitney test was applied to determine the significance of differences. Two samplings were considered to belong to different general populations if $p<0.05$.

\section{Results and Discussion}

Structural condition of peritoneal macrophage membranes. At the first research stage we assessed a lipid spectrum of peritoneal macrophage membranes (Table 1). Spark plasma exposure for $60,300,600$, and 1,200 s revealed a successive increase of CS ester (CSEs) fractions by 23.7-34.0\%. The decrease in phosphatidylcholine fraction by $40.0-46.8 \%$ was found when exposure time was 300,600 , and $1,200 \mathrm{~s}$. In addition, if exposure time is $1,200 \mathrm{~s}$, there is a significant decrease in CS amount, by $14.7 \%$, as well as the decrease of quantitative amount of such PL groups as phosphatidylethanolamine and lysophosphatidylcholine - by 49.0 and $60.4 \%$, respectively. CSEs is the main form of CS supply in a cell, and the increase of their proportion can be related to possible oxidative reactions after spark plasma radiation, since the increase of total CS (CS+CSEs) in cells is known to be a protective response of a cell providing cell structural stability and protection against oxidation products [15, 16]. Phosphatidylcholine and phosphatidylethanolamine play a key role in membrane bilayer stabilization. The reduction of their amount can be related to the oxidation of certain PL fractions and result in the alteration of biophysical properties of cytolemma. Due to the fact that lysophosphatidylcholine exhibits the properties of a macrophage chemoattractant and mitogen, its reduction can have an effect on functional capabilities of a cell. Generally, the lipid spectrum changes at exposure time being $1,200 \mathrm{~s}$ suggests the switching cell protective reactions [15]. Moreover, the $\mathrm{CS} / \mathrm{PL}$ ratio increases by 1.4 times, when being exposed within 1,200 s. It indicates the redistribution of relationship of the main lipid constituents and can result in the functional activity change of cell membranes.

UV radiation of a quartz lamp influences the lipid composition of peritoneal macrophage membranes to a greater extent than plasma radiation (See Table 1). 1,200-second exposure causes a significant reduction of lysophosphatidylcholine, phosphatidylcholine, and phosphatidylethanolamine by $53.2,72.9$, and $52.4 \%$, respectively. CSEs proportion increases by $31.1 \%$, the CS/PL ratio increases by 1.7 times. Similar "protective" reconstruction of a lipid spectrum is characterized by enhanced stiffness of cell membranes and can lead to the limitation of cell functional capabilities.

The effect of gas discharged plasma radiation and UV radiation of a quartz lamp on the alterations in lipid spectrum of peritoneal macrophages is of oxidative nature, there is the decrease of $\mathrm{PL}$, while CSEs is increasing. However, CS/PL ratio after quartz lamp 
Table 1

Lipid composition of rat peritoneal macrophages after gas discharge exposure (\%)

\begin{tabular}{|c|c|c|c|c|c|c|c|c|c|c|}
\hline \multicolumn{2}{|c|}{ Exposure type and time } & LPC & SPH & $P C$ & PE & FFA & CS & TAG & CSES & CS/PL \\
\hline \multicolumn{2}{|c|}{ Before exposure } & $2.05 \pm 0.20$ & $7.39 \pm 0.27$ & $3.65 \pm 0.39$ & $2.06 \pm 0.32$ & $13.74 \pm 1.44$ & $26.79 \pm 0.87$ & $5.32 \pm 0.61$ & $35.66 \pm 2.83$ & $1.87 \pm 0.10$ \\
\hline \multirow{5}{*}{$\begin{array}{l}\text { Pilimin } \\
\text { series IR-10 }\end{array}$} & $30 \mathrm{~s}$ & $1.96 \pm 0.13$ & $8.37 \pm 0.65$ & $4.09 \pm 0.50$ & $1.63 \pm 0.20$ & $13.33 \pm 0.79$ & $25.55 \pm 1.26$ & $4.83 \pm 0.35$ & $43.16 \pm 2.01$ & $1.49 \pm 0.17$ \\
\hline & $60 \mathrm{~s}$ & $1.61 \pm 0.13$ & $7.37 \pm 1.07$ & $3.76 \pm 0.37$ & $1.69 \pm 0.16$ & $11.29 \pm 0.42$ & $25.00 \pm 1.08$ & $4.76 \pm 0.52$ & $\begin{array}{c}44.13 \pm 0.94^{*} \\
(p=0.032)\end{array}$ & $1.99 \pm 0.34$ \\
\hline & $300 \mathrm{~s}$ & $1.43 \pm 0.19$ & $6.44 \pm 0.46$ & $\begin{array}{l}1.94 \pm 0.24^{*} \\
(p=0.012)\end{array}$ & $1.27 \pm 0.20$ & $11.22 \pm 0.84$ & $23.46 \pm 1.46$ & $5.51 \pm 0.58$ & $\begin{array}{c}49.01 \pm 1.74^{*} \\
(p=0.007)\end{array}$ & $2.25 \pm 0.20$ \\
\hline & $600 \mathrm{~s}$ & $1.65 \pm 0.20$ & $7.21 \pm 0.52$ & $\begin{array}{l}2.19 \pm 0.29^{*} \\
(p=0.020)\end{array}$ & $1.42 \pm 0.18$ & $13.62 \pm 1.44$ & $24.65 \pm 1.44$ & $5.65 \pm 0.55$ & $\begin{array}{c}45.87 \pm 2.25^{*} \\
(p=0.038)\end{array}$ & $2.19 \pm 0.13$ \\
\hline & $1,200 \mathrm{~s}$ & $\begin{array}{c}0.81 \pm 0.19^{*} \\
(p=0.008)\end{array}$ & $6.12 \pm 0.51$ & $\begin{array}{l}1.94 \pm 0.26^{*} \\
(p=0.014)\end{array}$ & $\begin{array}{l}1.05 \pm 0.10^{*} \\
(p=0.013)\end{array}$ & $13.17 \pm 1.67$ & $\begin{array}{c}22.84 \pm 0.87^{*} \\
(p=0.036)\end{array}$ & $4.68 \pm 0.37$ & $\begin{array}{c}47.82 \pm 3.32^{*} \\
(p=0.025)\end{array}$ & $\begin{array}{l}2.58 \pm 0.23^{*} \\
(p=0.025)\end{array}$ \\
\hline \multirow{5}{*}{ DBK-9 } & $30 \mathrm{~s}$ & $1.85 \pm 0.18$ & $8.21 \pm 1.35$ & $5.08 \pm 1.01$ & $2.39 \pm 0.56$ & $15.12 \pm 1.51$ & $23.70 \pm 0.69$ & $5.37 \pm 0.61$ & $33.71 \pm 3.40$ & $1.60 \pm 0.25$ \\
\hline & $60 \mathrm{~s}$ & $1.43 \pm 0.28$ & $8.50 \pm 1.60$ & $4.59 \pm 1.06$ & $2.44 \pm 0.56$ & $14.99 \pm 0.94$ & $24.06 \pm 1.28$ & $5.03 \pm 0.33$ & $37.06 \pm 2.98$ & $1.71 \pm 0.48$ \\
\hline & $300 \mathrm{~s}$ & $1.53 \pm 0.14$ & $8.75 \pm 1.63$ & $3.52 \pm 0.59$ & $1.90 \pm 0.56$ & $13.06 \pm 1.0$ & $25.26 \pm 1.97$ & $5.22 \pm 0.17$ & $37.36 \pm 5.24$ & $1.89 \pm 0.40$ \\
\hline & $600 \mathrm{~s}$ & $1.60 \pm 0.14$ & $9.45 \pm 0.32$ & $3.72 \pm 0.82$ & $2.31 \pm 0.15$ & $14.06 \pm 0.88$ & $25.47 \pm 1.12$ & $4.38 \pm 0.44$ & $35.75 \pm 2.94$ & $1.80 \pm 0.22$ \\
\hline & $1,200 \mathrm{~s}$ & $\begin{array}{c}0.96 \pm 0.08 * \\
(p=0.014)\end{array}$ & $5.74 \pm 0.99$ & $\begin{array}{l}0.99 \pm 0.06^{*} \\
(p=0.008)\end{array}$ & $\begin{array}{l}0.98 \pm 0.13^{*} \\
(p=0.036)\end{array}$ & $14.52 \pm 1.25$ & $26.69 \pm 0.49$ & $3.86 \pm 0.34$ & $\begin{array}{c}46.74 \pm 1.47^{*} \\
(p=0.047)\end{array}$ & $\begin{array}{c}3.23 \pm 0.43^{*} \\
(p=0.014)\end{array}$ \\
\hline
\end{tabular}

N o t e. LPC: lysophosphatidylcholine, SPH: sphingomyelin, PC: phosphatidylcholine, PE: phosphatidylethanolamine, FFA: free fatty acids, CS: cholesterol, TAG: triacylglycerides, CSEs: cholesterol esters, CS/PL: the ratio of cholesterol fraction to total phospholipids; * significant difference with a control group (before exposure).

Table 2

Indices of membrane microviscosity of peritoneal macrophages after gas discharge exposure (relative units)

\begin{tabular}{lcccc}
\hline \multirow{2}{*}{ Time exposure } & \multicolumn{2}{c}{ Pilimin series $\mathbb{R}-10$} & \multicolumn{2}{c}{ DBK-9 } \\
\cline { 2 - 5 } & Lipid bilayer & $\begin{array}{c}\text { Protein-lipid } \\
\text { interactions }\end{array}$ & Lipid bilayer & $\begin{array}{c}\text { Protein-lipid } \\
\text { interactions }\end{array}$ \\
\hline Unexposed & $0.421 \pm 0.024$ & $0.419 \pm 0.008$ & $0.421 \pm 0.024$ & $0.419 \pm 0.008$ \\
\hline $0 \mathrm{~s}$ & $0.375 \pm 0.025$ & $0.390 \pm 0.006^{*}(p=0.036)$ & $0.417 \pm 0.032$ & $0.397 \pm 0.021$ \\
$60 \mathrm{~s}$ & $0.366 \pm 0.017$ & $0.355 \pm 0.027^{*}(p=0.013)$ & $0.412 \pm 0.023$ & $0.391 \pm 0.015$ \\
\hline $300 \mathrm{~s}$ & $0.347 \pm 0.021$ & $0.350 \pm 0.016^{*}(p=0.016)$ & $0.361 \pm 0.014$ & $0.359 \pm 0.016^{*}(p=0.010)$ \\
$600 \mathrm{~s}$ & $0.330 \pm 0.015^{*}(p=0.031)$ & $0.357 \pm 0.019^{*}(p=0.022)$ & $0.317 \pm 0.024^{*}(p=0.016)$ & $0.342 \pm 0.013^{*}(p=0.019)$ \\
\hline $1,200 \mathrm{~s}$ & $0.261 \pm 0.016^{*}(p=0.008)$ & $0.357 \pm 0.021^{*}(p=0.043)$ & $0.254 \pm 0.022^{*}(p=0.004)$ & $0.322 \pm 0.017^{*}(p=0.009)$ \\
\hline
\end{tabular}

* Significant difference of values with a control group.

radiation exposure is $36 \%$ higher indicating the more intense oxidation of PL.

The altered lipid composition of peritoneal macrophages after physical effects can indicate the change of membrane viscosity and cell rigidity. Adequate functioning of plasma membrane is known to be determined by microviscosity properties. Therefore, a fluorescent pyrene probe was used to study membrane microviscosity in lipid-lipid and protein-lipid interaction areas. The eximerization coefficient reduction of a pyrene probe suggests microviscosity growth. Spark plasma radiation and UV radiation of a quartz lamp are found to result in gradual increase of membrane microviscosity of peritoneal macrophages in a lipid bilayer if exposure time increases: if the exposure time is $1,200 \mathrm{~s}$, microviscosity grows by 38 and $39.7 \%$, respectively, compared to a control series (Table 2 ). In the protein-lipid interaction area microviscosity increases by $6.92-14.80 \%$ at any spark plasma exposure mode. $14.32-23.15 \%$ increase of microviscosity after UV radiation of a quartz lamp is observed in the area of and protein-lipid interaction if the exposure time is 300 , 600 , and 1,200 s. Quartz lamp radiation results in more significant microviscosity growth in and protein-lipid interaction areas compared to plasma radiation, it is likely to be due to a higher photon flow of UV radiation of 


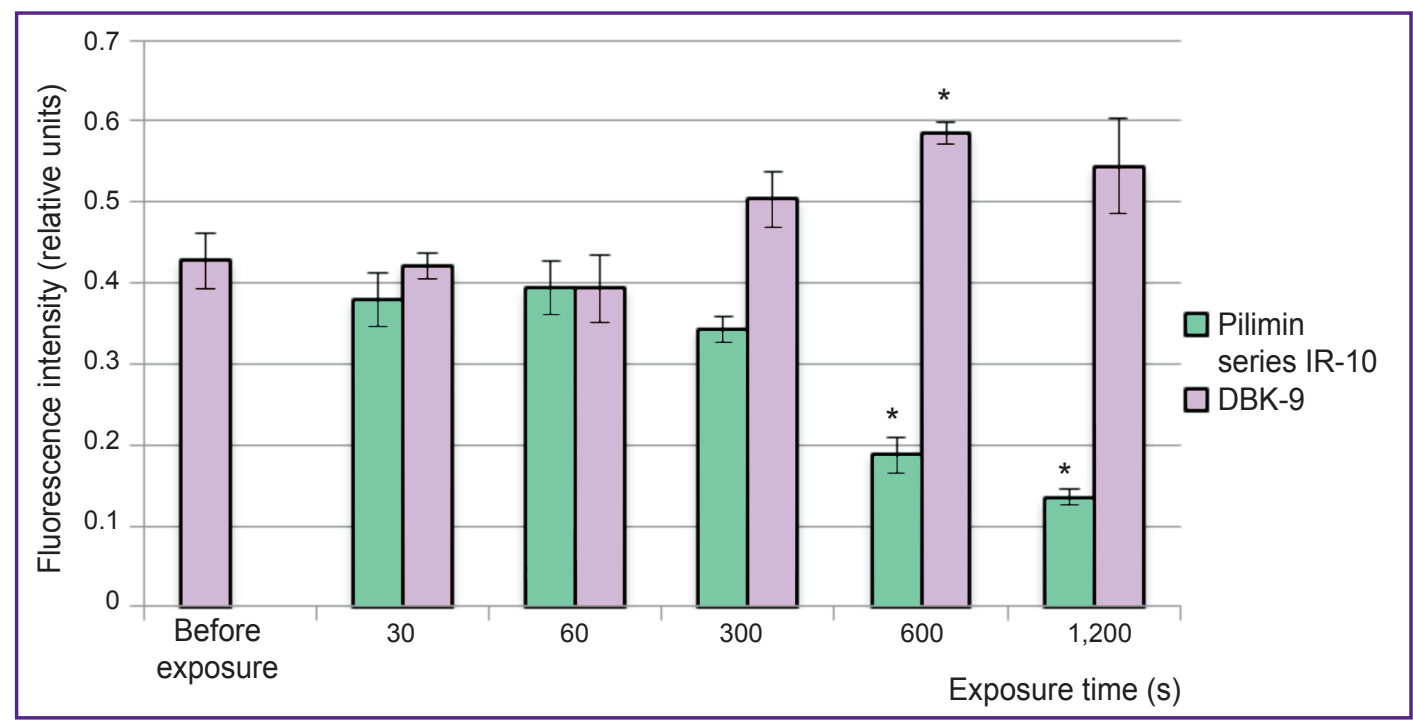

Fluorescence intensity of 1,6-diphenyl-1,3,5-hexatrien probe in a bilayer of peritoneal macrophages

* Significant difference of values with a control group, $p<0.05$

a quartz lamp [17]. It is commonly known that membrane microviscosity increases in the area of lipid-lipid and protein-lipid interactions can result in the conformational alteration of membrane enzymes, intramembrane protein mobility and activity, impaired selective permeability and operation of cell receptors [18]

Fatty acids of PL provide plastic and flow properties of a bilayer. Therefore, in addition, to estimate the structural organization of fatty acids of PL (PL tails) we analyzed fluorescence of 1,6-diphenyl-1,3,5-hexatrien probe, which enables to study the condition of a hydrophobic hydrocarbon layer of cell plasma membranes. There was found the hydrophobicity decrease of fatty acids of phospholipid membranes after spark plasma radiation by 56.3 and $68.5 \%$, respectively, if the exposure time was 600 and $1,200 \mathrm{~s}$ (See Figure).

1,6-diphenyl-1,3,5-hexatrien probe is known to be

Table 3

Phagocytic activity of peritoneal macrophages after gas discharge exposure

\begin{tabular}{|c|c|c|c|c|}
\hline \multirow{2}{*}{ Exposure time } & \multicolumn{2}{|c|}{ Pilimin series IR-10 } & \multicolumn{2}{|c|}{ DBK-9 } \\
\hline & $\mathrm{PI}(\%)$ & PN & $\mathrm{PI}(\%)$ & PN \\
\hline Before exposure & $53.43 \pm 1.23$ & $3.52 \pm 0.06$ & $53.43 \pm 1.23$ & $3.52 \pm 0.06$ \\
\hline $30 \mathrm{~s}$ & $54.14 \pm 1.14$ & $3.69 \pm 0.15$ & $54.80 \pm 1.19$ & $3.58 \pm 0.17$ \\
\hline $60 \mathrm{~s}$ & $\begin{array}{l}57.88 \pm 1.13 \\
(p=0.034)^{*}\end{array}$ & $3.68 \pm 0.15$ & $55.33 \pm 1.69$ & $3.50 \pm 0.11$ \\
\hline $300 \mathrm{~s}$ & $54.63 \pm 1.39$ & $3.70 \pm 0.12$ & $52.67 \pm 1.86$ & $3.48 \pm 0.11$ \\
\hline $600 \mathrm{~s}$ & $53.0 \pm 1.12$ & $\begin{array}{l}3.83 \pm 0.13 \\
(p=0.040)^{*}\end{array}$ & $55.25 \pm 2.50$ & $3.66 \pm 0.14$ \\
\hline $1,200 \mathrm{~s}$ & $50.17 \pm 1.66$ & $3.47 \pm 0.14$ & $55.20 \pm 1.02$ & $3.51 \pm 0.12$ \\
\hline
\end{tabular}

Note. PI: phagocytic index, PN: phagocytic number; * significant difference of values with a control group. located in a hydrophobic area parallel to fatty acid chains. Hydrophobicity reduction can be related to the regularity decrease of hydrocarbon tails of $\mathrm{PL}$, the formation of clusters and dynamic membrane defects resulting in the enhanced nonspecific cell permeability $[19,20]$.

Cell membrane hydrophobicity tends to increase in all the exposure modes selected after UV radiation of a quartz lamp. The exposure lasting $600 \mathrm{~s}$, hydrophobicity was found to grow by $36.7 \%$. Hydrophobicity increase can indicate the thickening of a phospholipid bilayer and the membrane permeability reduction $[19,20]$.

Spark plasma radiation and UV radiation of a quartz lamp result in oppositely directed alterations of hydrophobicity of phospholipid fatty acids. Membrane hydrophobicity decreases under gas discharged plasma radiation and increases under UV lamp radiation that can be related, firstly, to different mechanisms of the factors used, and secondly, spark plasma radiation is known to be pulsed and 400 times lower against UV radiation of a quartz lamp [17].

Cytoplasmic membrane is known to play a key role in determining normal functioning of both single organelles and a cell in whole. The alterations in membrane structural components can be called regulatory, since they determine functional condition of cells. The observed rearrangements in a lipid spectrum of peritoneal macrophages, microviscosity increase and the changes of membrane hydrophobicity can lead to both the limitation, as well as the enhancement of cell capabilities $[2,15]$.

Functional condition of peritoneal macrophages. When exposed to spark 


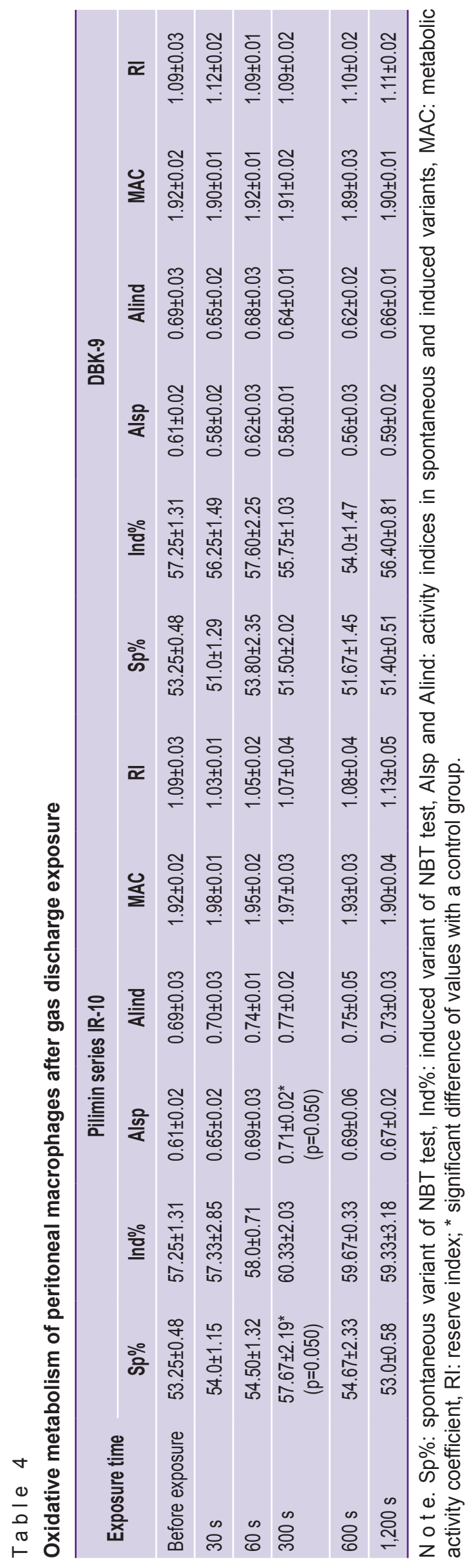

plasma radiation for $60 \mathrm{~s}$, peritoneal macrophages were found to have a significant growth of phagocytic index by $8.3 \%$ (Table 3 ). The exposure time being $600 \mathrm{~s}$, the phagocytic number increases by $8.8 \%$. Phagocytic index growth suggests an increase of the number of cells participating in phagocytosis, and the phagocytic number increase indicates high absorbing capacity [1].

The analysis of the indices of metabolic activity of macrophages shows the activation of oxygen-dependent cell metabolism when exposed to spark plasma radiation for $300 \mathrm{~s}$ (Table 4). Generation intensity by reactive oxygen species cells is determined mainly by NADPHoxidase activity, which depends on an initiating factor concentration and stimulation time [21]. UV radiation of a quartz lamp had no effect on phagocytic activity and the state of oxygen-dependent metabolism of peritoneal macrophages.

When estimating phagocytic activity by NBT test it is possible to record only absorption capacity of cells and the ability to produce superoxide anion radical, therefore, during the next stage we studied luminaldependent chemiluminescence of cells, which enables to assess the formation of reactive oxygen species by cells including superoxide anion radical, hydroxyl radical, singlet oxygen, hypocloride and general functional state of phagocytes. The experiment showed a significant increase of spontaneous chemiluminescence after spark plasma radiation exposure within 60 and $300 \mathrm{~s}$ by 65.3 and $116.5 \%$, respectively (Table 5 ). If exposure time is 600 and $1,200 \mathrm{~s}$, spontaneous chemiluminescence tends to decrease. There is no evident peak, though when a maximum level is achieved it decreases by 70.7 and $74.6 \%$. 62.9$74.7 \%$ increase of spontaneous chemiluminescence was found under UV radiation of a quartz lamp, the exposure time being 300,600 , and $1,200 \mathrm{~s}$. The time when maximum level of chemiluminescence occurs increases by $29.6 \%$ if exposure time is $1,200 \mathrm{~s}$. Luminaldependent chemiluminescence shows the activation of macrophages, which is due to the interaction of cells with reactive oxygen species formed as a result of radiation. Photobiological effects are considered to be implemented through a cascade of oxidative reactions, and an oxidative stress of lower intensity performs a regulatory function $[22,23]$.

To evaluate cell aptitude to respond on simulation, we analyzed the level of induced chemiluminescence. The exposure modes of 30,60 , and 300 s of spark plasma radiation were found to contribute to chemiluminescence activation by 1.6-3.9 times. When peritoneal macrophages were exposed to UV radiation of a quartz lamp within 300 and $600 \mathrm{~s}$, induced chemiluminescence was observed to increase by 1.3 and 1.4 times, respectively. Spark plasma radiation was shown to reduce the time of maximal chemiluminescence level occurrence, i.e. the time when "oxygen explosion" occurs, while UV radiation of a quartz lamp increases the reaction time at both: spontaneous and induced test forms. 


\section{BIOMEDICAL INVESTIGATIONS}

Table 5

Luminal-dependent chemiluminescence in rat peritoneal macrophages

\begin{tabular}{|c|c|c|c|c|c|c|c|c|}
\hline \multirow{3}{*}{ Exposure time } & \multicolumn{4}{|c|}{ Pilimin series IR-10 } & \multicolumn{4}{|c|}{ DBK-9 } \\
\hline & \multicolumn{2}{|c|}{$\begin{array}{l}\text { Spontaneous } \\
\text { chemiluminescence }\end{array}$} & \multicolumn{2}{|c|}{$\begin{array}{c}\text { Induced } \\
\text { chemiluminescence }\end{array}$} & \multicolumn{2}{|c|}{$\begin{array}{c}\text { Spontaneous } \\
\text { chemiluminescence }\end{array}$} & \multicolumn{2}{|c|}{$\begin{array}{c}\text { Induced } \\
\text { chemiluminescence }\end{array}$} \\
\hline & $\mathrm{mV} / \mathrm{min}$ & $\min$ & $\mathrm{mV} / \mathrm{min}$ & $\min$ & $\mathrm{mV} / \mathrm{min}$ & $\min$ & $\mathrm{mV} / \mathrm{min}$ & $\min$ \\
\hline Before exposure & $0.170 \pm 0.029$ & $17.75 \pm 0.85$ & $0.223 \pm 0.014$ & $9.38 \pm 0.80$ & $0.170 \pm 0.029$ & $17.75 \pm 0.85$ & $0.223 \pm 0.014$ & $9.38 \pm 0.80$ \\
\hline $30 \mathrm{~s}$ & $0.199 \pm 0.037$ & $18.0 \pm 0.41$ & $\begin{array}{l}0.359 \pm 0.049 \\
(p=0.010)^{*}\end{array}$ & $7.0 \pm 1.13$ & $0.218 \pm 0.019$ & $16.50 \pm 1.44$ & $0.244 \pm 0.020$ & $9.33 \pm 1.33$ \\
\hline $60 \mathrm{~s}$ & $\begin{array}{l}0.281 \pm 0.029 \\
(p=0.043)^{*}\end{array}$ & $17.33 \pm 1.23$ & $\begin{array}{l}0.817 \pm 0.137 \\
(p=0.001)^{*}\end{array}$ & $9.33 \pm 1.54$ & $0.211 \pm 0.019$ & $16.80 \pm 2.35$ & $0.247 \pm 0.015$ & $9.20 \pm 1.77$ \\
\hline $300 \mathrm{~s}$ & $\begin{array}{l}0.368 \pm 0.054 \\
(p=0.037)^{*}\end{array}$ & $17.20 \pm 0.86$ & $\begin{array}{l}0.866 \pm 0.096 \\
(p=0.001)^{*}\end{array}$ & $12.67 \pm 1.50$ & $\begin{array}{l}0.283 \pm 0.017 \\
(p=0.030)^{*}\end{array}$ & $13.33 \pm 1.76$ & $\begin{array}{l}0.295 \pm 0.005 \\
(p=0.044)^{*}\end{array}$ & $7.75 \pm 0.75$ \\
\hline $600 \mathrm{~s}$ & $0.086 \pm 0.021$ & $\begin{array}{l}5.20 \pm 0.80 \\
(p=0.019)^{*}\end{array}$ & $0.243 \pm 0.047$ & $\begin{array}{c}3.80 \pm 0.49 \\
(p=0.0054)^{*}\end{array}$ & $\begin{array}{l}0.297 \pm 0.011 \\
(p=0.011)^{*}\end{array}$ & $13.71 \pm 1.38$ & $\begin{array}{c}0.313 \pm 0.021 \\
(p=0.008)^{*}\end{array}$ & $8.17 \pm 0.75$ \\
\hline $1,200 \mathrm{~s}$ & $0.079 \pm 0.023$ & $\begin{array}{l}4.50 \pm 0.87 \\
(p=0.030)^{*}\end{array}$ & $0.174 \pm 0.014$ & $\begin{array}{l}3.20 \pm 0.20 \\
(p=0.004)^{*}\end{array}$ & $\begin{array}{c}0.277 \pm 0.028 \\
(p=0.030)^{*}\end{array}$ & $\begin{array}{l}23.0 \pm 1.64 \\
(p=0.037)^{*}\end{array}$ & $0.253 \pm 0.026$ & $\begin{array}{l}18.50 \pm 1.09 \\
(p=0.002)^{*}\end{array}$ \\
\hline
\end{tabular}

* Significant difference of values with a control group.

Thus, the oxidation of PL proceeds less intensively under spark plasma radiation. Membrane microviscosity in the area of lipid-lipid and protein-lipid interactions enhances to a greater degree after UV radiation of a quartz lamp. Hydrophobicity of PL of fatty acids decreases under spark plasma radiation and increases under UV radiation of a quartz lamp. Spark plasma radiation in contrast to UV radiation of a quartz lamp causes the growth of the number of cells participating in phagocytosis, the enhancement of absorbing capacity and oxygen-dependent metabolism of peritoneal macrophages. The period of an "oxygen explosion" of macrophages reduces after plasma radiation, and increases when exposed to UV radiation of a quartz lamp.

Conclusion. Spark plasma radiation compared to UV lamp radiation contributes to the enhancement of phagocytic activity of peritoneal macrophages in less continuous modes, the effects under study being more pronounced. The study findings enable to reveal optimal modes for functional cell activity after gas discharge exposure.

Study Funding and Conflicts of Interest. The study was not funded by any sources, and the authors have no conflicts of interest related to the present study.

\section{References}

1. Lyamina S.V., Malyshev I.Y. Macrophage polarization in the modern concept of immune response development. Fundamental'nye issledovaniya 2014; 10(5): 930-935.

2. Artyukhov V.G., Basharina O.V., Zimchenkova O.V., Ryazantsev S.V. The effect of UV light on subpopulation composition and expression of membrane markers of human blood lymphocytes. Radiatsionnaya biologiya.
Radioekologiya 2016; 56(1): 73-81, https://doi.org/10.7868/ s086980311506003x.

3. Köberlin M.S., Heinz L.X., Superti-Furga G. Functional crosstalk between membrane lipids and TLR biology. Curr Opin Cell Biol 2016; 39: 28-36, https://doi.org/10.1016/j.ceb. 2016.01.010.

4. Sasai Y., Kondo S., Yamauchi Y., Kuzuya M. Plasma surface modification of polymer substrate for cell adhesion control. J Photopolym Sci Technol 2010; 23(4): 595-598, https://doi.org/10.2494/photopolymer.23.595.

5. Rupf S., Lehmann A., Hannig M., Schäfer B., Schubert A., Feldmann U., Schindler A. Killing of adherent oral microbes by a non-thermal atmospheric plasma jet. J Med Microbiol 2009; 59(2): 206-212, https://doi.org/10.1099/jmm.0.013714-0.

6. Ivanova I.P., Zaslavskaya M.I. Biocydic effect of the spark discharge non-coherent impulse radiation in experiments in vitro and in vivo. Sovremennye tehnologii v medicine 2009; 1: $28-31$.

7. Arkhipova E.V., Ivanova I.P. The effect of non-coherent impulse radiation on functional status of mononuclear cells in experiment. Sovremennye tehnologii $v$ medicine 2013; 5(1): 27-31.

8. Arkhipova E.V., Ivanova I.P. Microviscosity and lipid peroxidation of peritoneal macrophages after UV radiation and gas-discharged plasma radiation. Meditsinskiy akademicheskiy zhurnal 2016; 16(4): 46-47.

9. Trofimova S.V., Burkhina O.E., Piskaryov I.M., Ichetkina A.A., Solovyova T.I., Astafieva K.A., Pugina E.S., Ivanova I.P. The effect of gas-discharge plasma radiation on erythrocyte protein modification. Sovremennye tehnologii $v$ medicine 2014; 6(3): 14-21.

10. Ivanova I.P., Trofimova S.V., Karpel Vel Leitner N., Aristova N.A., Arkhipova E.V., Burkhina O.E., Sysoeva V.A., Piskaryov I.M. The analysis of active products of spark discharge plasma radiation determining biological effects in tissues. Sovremennye tehnologii v medicine 2012; 2: 20-30.

11. Kanazawa S., Kawano H., Watanabe S., Furuki T., 
Akamine S., Ichiki R., Ohkubo T., Kocik M., Mizeraczyk J. Observation of $\mathrm{OH}$ radicals produced by pulsed discharges on the surface of a liquid. Plasma Sources Sci Technol 2011; 20(3): 034010, https://doi.org/10.1088/0963-0252/20/3/034010.

12. Tvorogova M.G., Isaeva E.L., Prokazova N.V., Rozhkova T.A., Kukharchuk V.V., Titov V.N. The determination of lipid composition of high-density lipoproteids by silica gel thin-layer chromatography. Klinicheskaya laboratornaya diagnostika 1998; 4: 13-16.

13. Samoylova A.A. Izmerenie mikrovyazkosti membran eritrotsitov metodom lateral'noy diffuzii gidrofobnogo zonda pirena. Metod. Razrabotka [Measurement of erythrocyte membrane microviscosity by lateral diffusion of hydrophobic pyrene probe. Technique. Development]. Krasnoyarsk: Krasnoyar. gos. un-t; 2006.

14. Ranall M., Gabrielli B., Gonda T. Highcontent imaging of neutral lipid droplets with 1,6-diphenylhexatriene. Biotechniques 2011; 51(1), https:// doi.org/10.2144/000113702.

15. Kiselev O.I., Sergeeva I.V., Sologub T.V., Tikhonova E.P., Bulygin G.V. Structural and metabolic characteristics of cells and their functional capabilities. Epidemiologiya $i$ infektsionnye bolezni 2015; 20(5): 52-56.

16. Yesimova I.Ye., Novitsky V.V., Urazova O.I., Khasanova R.R., Koshkina A.A., Churina Ye.G. The causes of dysregulation of immune response in pulmonary tuberculosis: the role of disorders of the initial state of immunological reactivity of the organism. Byulleten' sibirskoy meditsiny 2012; 11(4): 93-98.

17. Piskarev I.M., Ivanova I.P., Trofimova S.V. Comparison of chemical effects of UV radiation from spark discharge in air and a low-pressure mercury lamp. High Energy Chem 2013; 47(5): 247-250, https://doi.org/10.1134/s0018143913050093.

18. Rebrova T.Yu., Afanasiev S.A., Putrova O.D., Popov S.V. Age-related features of microviscosity of erythrocyte membranes in experimental cardiosclerosis. Uspekhi gerontologii 2012; 25(4): 644-647.

19. Loura L.M.S., Ramalho J.P.P. Recent developments in molecular dynamics simulations of fluorescent membrane probes. Molecules 2011; 16(12): 5437-5452, https://doi. org/10.3390/molecules16075437.

20. do Canto A.M., Robalo J.R., Santos P.D., Carvalho A.J., Ramalho J.P., Loura L.M. Diphenylhexatriene membrane probes DPH and TMA-DPH: a comparative molecular dynamics simulation study. Biochim Biophys Acta 2016; 1858(11): 26472661, https://doi.org/10.1016/j.bbamem.2016.07.013.

21. Sheppard F.R., Kelher M.R., Moore E.E., McLaughlin N.J., Banerjee A., Silliman C.C. Structural organization of the neutrophil NADPH oxidase: phosphorylation and translocation during priming and activation. J Leukoc Biol 2005; 78(5): 1025-1042.

22. Gamaley I.A., Klyubin I.V. Roles of reactive oxygen species: signaling and regulation of cellular functions. Int Rev Cytol 1999; 203-255, https://doi.org/10.1016/s00747696(08)61568-5.

23. Hattori H., Subramanian K.K., Sakai J., Jia Y., Li Y., Porter T.F., Loison F., Sarraj B., Kasorn A., Jo H., Blanchard C., Zirkle D., McDonald D., Pai S.Y., Serhan C.N., Luo H.R. Small-molecule screen identifies reactive oxygen species as key regulators of neutrophil chemotaxis. Proc Natl Acad Sci USA 2010; 107(8): 3546-3551, https://doi.org/10.1073/ pnas.0914351107. 